\title{
Managing fisheries in a changing climate
}

\section{No need to wait for more information: industrialized fishing is already wiping out stocks.}

Sir - Your News story "Climate findings let fishermen off the hook" (Nature 428, 4; 2004) offers the view that climate warming and other environmental changes may be just as important as overfishing in driving worldwide declines of fish stocks. It also suggests that climate may be responsible when depleted stocks fail to recover, and that fishery management and climate research should be more closely tied to each other.

While it has been known for many years that climate variability can affect fish recruitment (the replenishment of stocks with juveniles), especially at the margins of species' ranges, there is at present no evidence that worldwide declines are linked in any major way to climate change. Large declines in marine fish communities have always coincided precisely with the onset of industrialized fishing (see R. A. Myers \& B. Worm,
Nature 423, 280-283; 2003), which occurred at different times in different regions. Likewise, historical declines of marine megafauna, such as large groundfish, turtles or mammals, have always been related to the introduction of new fishing techniques and increased exploitation by European colonists (J. B. C. Jackson et al. Science 293, 629-637; 2001), not to climate change.

Spectacular collapses such as those of Eastern Canadian cod stocks, which at first were attributed to climate change, turned out on closer analysis to be solely related to overfishing (R. A. Myers et al. Ecol. Appl. 7, 91-106; 1997).

We emphasize that heavily overfished stocks may be more sensitive to climate variability, because loss of diversity among locally adapted populations has impaired resilience. Indeed, these findings do not let fishermen (or fishery managers) "off the hook", but underline the need for more conservative management.

The abundance of spawning and juvenile fish is estimated for most commercial fisheries each year using scientific surveys and fisheries data. This information already integrates actual climate influences and can thus be used to determine optimal fishing quotas.

The problem is that scientific recommendations are almost always exceeded, and overfishing is allowed to continue unabated, despite better knowledge. This problem is a political one. There is already sufficient information available to manage global fisheries sustainably, with or without any additional understanding of climate change.

Boris Worm, Ransom A. Myers Biology Department, Dalhousie University, Halifax, Nova Scotia B3H 4J1, Canada

\section{Colourful history of Japan's rat resources \\ Sir - As passionate rat researchers we} were delighted to see the rat on the cover of the 1 April 2004 issue of Nature. It is little known that Japan has a long history of rat research, including studies on coatcolour inheritance (see picture) that date back to the eighteenth century. Chingansodategusa, a Japanese guidebook on the breeding of fancy rats and mice, was published in 1787, during the Edo period, when Japan's civilization was isolated from the rest of the world. Japan is still an island but, we hope, is not so isolated today.

Your News Feature "The Renaissance rat" (Nature 428, 464-466; 2004) hailed a remarkable rodent, but it did not mention a modern Japanese contribution to its research: the National Bio Resource Project for the Rat (www.anim.med.kyotou.ac.jp/nbr). This rat-strain repository, one of the largest in the world, currently has more than 200 rat strains, which are freely distributed - at no cost except shipping — to any interested rat researcher worldwide.

In addition, we also provide a database for more than 100 different phenotype parameters of the rat strains. This allows for strain ranking, a method by which the parameters are sorted and unexpected abnormal values in reference strains can be revealed. This project already covers almost 50 rat strains and will finally comprise 200. This sort of phenotype ranking has the

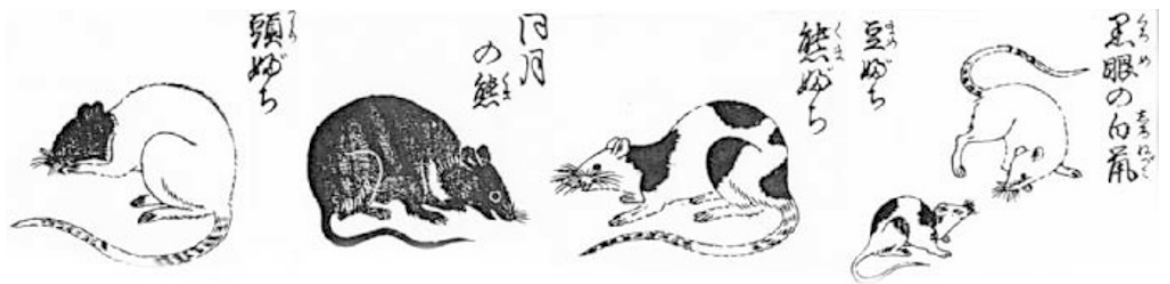

Rat race: illustrations from an eighteenth-century Japanese treatise on breeding rodents for colour.

potential to save rat researchers all over the world valuable time, money and animals.

Tadao Serikawa

Institute of Laboratory Animals, Graduate School of Medicine, Kyoto University, Yoshidakonoe-cho, Sakyo-ku, Kyoto 606-8501, Japan

\section{Multiskilled mouse rivals Renaissance rat}

Sir - The laboratory rat has obviously made immeasurable contributions to biomedical science and will continue to do so as long as humans conduct biological research. There are many considerations in the choice of a model organism, and rats certainly have their advantages, such as their relatively large size. But to suggest, as your News Feature "The Renaissance rat" (Nature 428, 464-466; 2004) does, that the rat is superior to the mouse for behavioural research is narrow-minded at best.

One only needs to work with a fairly small number of the more than 2,800 inbred, recombinant inbred, congenic, consomic or transgenic strains currently available at the Jackson Laboratory in Maine (www.jax.org) and it soon becomes apparent that not all mice "just don't have a plan”, nor are all mice particularly aggressive. Mouse strains range from the very docile, such as A/J, to the very aggressive, such as NZB/B1NJ, and from the not-so-smart, such as LP/J, to strains that perform quite well on various tests of complex learning: C57BL6/J, for example.

Indeed, a similar range of responses can be found for any other behaviour of interest, and it is this amazingly diverse behavioural repertoire that has made the mouse extremely useful for studies of the genetic basis of variation in behaviour (see Crawley et al. Psychopharmacology 132, 107-124; 1997).

\section{Richard A. Radcliffe}

University of Colorado Health Sciences Center, Department of Pharmaceutical Sciences, 4200 East Ninth Avenue, Denver, Colorado 80262, USA 